Ватиашвили М.P. Институт генетики Тбилисского Государственного университета им. И. Джавахишвили, г. Тбилиси, Грузия, kbloto@bk.ru

\title{
СОСТОЯНИЕ ПОЛЕЙ ОБЛАЧНЫХ СИСТЕМ И ОПАСНЫХ ЯВЛЕНИЙ ПОГОДЫ, РАЗВИВАЮЩИХСЯ В РЕГИОНЕ ЦЕНТРАЛЬНОГО КАВКАЗА
}

Введение

исследуются поля облачных систем, сопровождающихся опасными явлениями погоды. Для предотвращения града из них в 1967 г. были начаты производственные работы по защите сельхоз культур от градобитий Применялись комбинированный метод, методы конкуренции и ускорения процесса осадкообразования в объемах зон роста града и будущего градообразования. Анализ полученных результатов показал, что физическая эффективность противоградовых работ в Российской Федерации в среднем составляет 80-98\%, а Республике Грузия - 75-85\%

Выпадение града было обусловлено организационно-техническими причинами; недостаточной изученностью условий формирования попей облачности; отсутствием объективных критериев и схем засева градоопасных и градовых облаков; несвоевременной и недостаточной обработкой объемов зон роста града и будущего градообразования противоградовыми ракетами «Алазань», снаряженными частицами кристаллизующего реагента йодида серебра.

Материалы и методы: привлекались материалы визуальных и дистанционных методов наблюдений за развитием облачных систем, научные монографии и статьи, справочники и Атлас облаков, ежегодные отчеты противоградовых работ Военизированных служб региона Центрального Кавказа; физико-статистические методы оценки статистических характеристик параметров полей облачных систем, в основу которых положены пара-

Результаты метрические и непараметрические методы исследования.

Обсуждение и заключения:

Ключевые слова: выявлены особенности формирования полей облачности в синоптических процессах различных масштабов; построен грасик, на котором в зависимости от значений радиолокационных параметров, с вероятностью 90\%, выделены области с ливнями, слабыми, умеренными и катастрофическими градобитиями; получены уравнения для оценки нормы расхода количества ПГР «Алазань» и интенсивности стрельбы в градовых облаках; построены графики вероятности диагноза и сверхкраткосрочного прогноза сильных шквалов, в зависимости от значений аэросиноптических и радиолокационных параметров полей облачности.

многие из вышеперечисленных проблем практически решены в работах автора, которые защищены патентом и успешно применяются в противоградовой защите ВС Ставропольского края.

облако, град, шквалы, смерч, воздействие, ракеты, йодистое серебро. 
Vatiashvili M.R.

The Institute of Genetics of Tbilisi State University named after I. Dzhavakhishvili, Tbilisi, Georgia, kbloto@bk.ru

\section{The review of the condition of cloud systems fields and dangerous natural phenomena developing in the Central Caucasus region}

Abstract: $\quad$ the cloud systems fields accompanied by dangerous natural phenomena are under research. To prevent their hailing in 1967 shop-floor applications on protecting agricultural crops trom hail damage began. The combined method and methods of competition and process acceleration of sludging within hail and expected hail forming areas were applied. The analysis of the results has showen that average physical activity of anti-hail works in the Russian Federation is $80-98 \%$ and in the Republic of Georgia is $75-85 \%$.

Hailfall was stipulated by organizational and technical causes; poor investigation of conditions of cloud fields forming; the lack of objective criteria and seeding schemes of hail-damage and hail clouds; ill-timed and insufficien treatment of hail growth and expected hail forming areas by anti-hail rockets «Alazan» equipped with particles of argentum iodide reagent.

Materials and Methods: applied the materials of visual and remote observation methods of cloud systems developing, scientific monographs and articles, reference books and the Clouds Atlas, annual reports on anti-hail works of paramilitary services of the Central Caucasus region; physical and statistical evaluation methods of statistic parameters of cloud systems fields based on parametric and non-parametric research techniques.

Results: the peculiarities of cloud fields forming in different scales synoptic processes have been discovered; the areas of cloudbursts, light, moderate and disastrous hail damage depending on radar data with probability of $90 \%$ have been graphed; the equations for estimation of quantity application rate of AHR «Alazan» and shooting intensity in hail clouds have been derived; the probability of diagnosis and super short-term forecast of heavy squalls depending on aerosynoptical and radar data of cloud fields have been graphed.

Discussion and conclusions:

many of the abovementioned problems have been practically solved in author's patened works and are successlully applied in anti-hail protection of the Stavropol krai paramilitary services.

Keywords cloud, hail, squalls, whirlwind, influence, rockets, argentum iodide.

\section{Введение}

Поля облаков и облачных систем (ПООС) представляют собой совокупность водяного пара, взвешенных капель воды и кристаллов льда $[9,11-13,18,19]$. Они оказывают влияние на круговорот воды в природе; тепловой баланс системы «Земля - атмосфера»; формирование погоды; растительный и животный мир и т.д.

Прохождение ПООС сопровождается опасными явлениями (ОЯ) погоды, включающими в себя обложные осадки, интенсивные ливни и шквалы 
различной силы, градоопасные и градовые облака - соответственно объекты воздействия (OB) 1-2-й и 3-4-й категорий со значительным ущербом народного хозяйства, исчисляемыми сотнями млн долларов.

К такому региону относится Центральный Кавказ, охватывающий защищаемые территории (3Т) Военизированных служб (ВС) Республики Грузия и Российской Федерации [5, 6, 7]. Здесь с 1967 г. ведется противоградовая защита (ПГЗ) сельскохозяйственных (c/x) культур с применением комбинированного метода [2], методов конкуренции $[10,17]$ и ускорения процесса осадкообразования в зоне роста града (РГ) и будущего градообразования (БГ) [1] с применением артиллерийской и ракетной технологий засева.

В 1990 г. все ВС РФ (Северо-Кавказская, Краснодарская, Ставропольская ВС), работающие с применением артиллерийской технологии засева, были полностью переведены на ракетную технологию засева. Причины - дискретность засева, большой расход противоградовых снарядов (ПГС), невозможность быстрого засева объемов РГ и БГ в крупномасштабных градовых облаках, приводящих к их недозасеву и отрицательным результатам.

Физическая эффективность по ПГЗ в РФ в среднем составляет 80-98\%, а Республике Грузия - 75-85\%. Физическая эффективность по искусственному увеличению осадков (ИУО) в Республике Грузия составляла $10-15 \%$, с вероятностью 90-95\% [16].

В настоящее время площади ЗТ в РФ и Республике Грузия соответственно достигают 2 млн 421 тыс. га и 900 тыс. га. [5, 6, 7].

Несмотря на высокие показатели эффективности ПГЗ на ЗТ региона Центрального Кавказа ежегодно отмечались и по настоящее время все еще отмечаются отдельные случаи пропуска града, сопровождающиеся катастрофическими ливневыми осадками и шквалами более $25 \mathrm{~m} / \mathrm{c}$.

Ущерб с/х продукции был обусловлен:

- организационно-техническими причинами; недостаточной изученностью аэросиноптических условий формирования ПООС различных классов;

отсутствием новых объективных критериев их распознавания, совершенствованных схем засева и норм расхода противоградовых ракет «Алазань», снаряженных частицами кристаллизующего реагента (ЧКР) йодида серебра (AgI).

Целью представленной работы является:

- исследование условий формирования ПООС в синоптических процессах различных масштабов, выявление по данным визуальных и дистанционных методов наблюдений особенностей их генетико-морфологической классификации и связанных с ними типов градовых процессов (ГП);

- совершенствование существующих и разработка новых 
объективных критериев засева ОВ 1-4-й категорий и искусственного регулирования осадков (ИРО - искусственное увеличение или уменьшение осадков воздействием); разработка диагноза и сверхкраткосрочного прогноза шквалов различной силы в ПООС по аэросиноптическим данным и данным метеорологических радиолокаторов (МРЛ). совершенствование существуюших и разработка новых методов ПГЗ и искусственного увеличения осадков (ИУО), проводимых с помощью наземной ракетной технологии засева.

\section{Материалы и методы исследования}

В основу классификаций ПООС положены научные монографии и статьи, справочники и Атласы облаков, а также ежегодные отчеты по ПГЗ и ИУО, выполненных ВС региона Центрального Кавказа.

Визуальные наблюдения проводились с помощью наземных метеорологических станций (НМС), контактные измерения самолетами-метеолабораториями (СМЛ) [13], а дистанционные наблюдения - с помощью (МРЛ) [1, 14].

Для оценки статистических характеристик ПООС привлекались физико-статистические методы, в основу которых положены параметрические и непараметрические методы исследования [15].

\section{1. Особенности формирования ПООС синоптических мас-} гттабов

При анализе структуры и динамики развития ПООС, процессов зарождения и эволюции в них гидрометеоров наблюдаем явления различных синоптических масштабов: макромасштабные, мезомасштабные и микромасштабные синоптические процессы $[9,11-13,18,19]$.

Макромасштабные процессы характеризуются горизонтальной протяженностью от 1 тыс. до 10 тыс. км и продолжительностью их существования от 4 до 13 суток, составляя в среднем 5-7 суток. К ним относятся циклоны, антициклоны, безградиентные поля относительно пониженного и повышенного давления, теплые фронты, холодные основные и вторичные фронты, фронты окклюзии по типу холодного и теплого фронтов, волновые возмущения, наблюдаемые в Грузии с юга.

Мезомасштабные процессы характеризуются горизонтальной протяженностью от 2 до 100 км и продолжительностью существования от нескольких часов до 3 суток.

Микромасштабные процессы характеризуются размерами гидрометеоров с жидкими и/или твердыми облачными частицами и частицами осадков в облаках от 0,02 мкм до 5 см и продолжительностью их существования от нескольких секунд до десятков минут. 
2.

\section{Особенности генетико-морфологической классифика- ции ПООС по данным визуальных наблюдений}

Анализ многолетних материалов наблюдений показал, что, в зависимости от горизонтальных размеров и вертикальных движений воздушных масс, образуются различные классы ПООС. Они отличаются друг от друга внешним видом (морфологическая классификация) микроструктурой (микрофизическая классификация) и местом их зарождения (генетическая классификация) $[9,12,13,18,19]$. Они сопровождаются обложными осадками, интенсивными ливнями, грозоградовыми процессами и шквалами различной силы.

\section{Морфологическая классификация ПООС \\ Она включает в себя (табл. 1): облака нижнего яруса это - слоистые (Stratus, St), слоисто- кучевые (Stratocumulus, Sc) и слоисто-дождевые (Nimbo- stratus, Ns); облака среднего яруса это - высококучевые (Altocumulus, Ac) и высокослоистые (Altostratus, As); облака верхнего яруса это - перистые (Cirrus, Ci), перисто-ку- чевые (Cirrocumulus, Cc) и перисто-слоистые (Cirrostratus, Cs); облака вертикального развития это - кучевые плоские (Cumulus humilis, $\mathrm{Cu}$ hum), кучевые средние (Cumulus mediocris, $\mathrm{Cu}$ med), мощно-кучевые (Cumulus congestus, $\mathrm{Cu}$ - Cong), кучево-дождевые лысые (Cumulonimbus calvus, $\mathrm{Cb}$ calv) и кучево-дождевые волосатые (Cumulonimbus capil- latus, $\mathrm{Cb}$ cap).}

\section{Микрофизическая классификация ПООС}

Она характеризует фазовое состояние гидрометеоров, их размеры и концентрации (табл. 1) [11, 13]. В области положительных температур отмечаются жидкокапельные облака; температурного интервала от $0{ }^{\circ} \mathrm{C}$ до минус $30^{\circ} \mathrm{C}$ - смешанные облака, состоящие из переохлажденных капель до уровня изотермы минус $12^{\circ} \mathrm{C}$ и ледяных кристаллов при температуре ниже минус $12^{\circ} \mathrm{C}$; температур минус $30^{\circ} \mathrm{C}$, как правило, отмечаются кристаллические облака, хотя не исключена возможность существования переохлажденных капель даже при температуре менее минус $40^{\circ} \mathrm{C}$ [13].

Фазовое состояние облаков малой мощности и их однородное строение определяются в соответствии с температурой воздуха на уровне их нахождения. В умеренных широтах в теплый период года St и Sc являются жидкокапельными, так как они расположены в теплой части тропосферы, где температура воздуха $t>0{ }^{\circ} \mathrm{C}$; $\mathrm{Ci}, \mathrm{Cs}$ и $\mathrm{Cc}-$ кристаллическими, так как они расположены в области отрицательных температур $\left(t<-30^{\circ} \mathrm{C}\right)$ мощные облака типа $\mathrm{Ns}$ и $\mathrm{Cb}$ - смешанными так, как нижняя и верхняя их части соответственно расположены в области положительных и отрицательных температур, при 
этом размеры гидрометеоров в Сb обусловлены скоростями вертикальных движений воздушных масс и мощностями их переохлажденной части.

\section{Генетическая классификачия ПООС}

Она включает в себя облачные системы, формирующиеся в результате взаимодействия воздушных масс с различными физическими свойствами. Устойчивая воздушная масса характеризуется облаками $\mathrm{St}, \mathrm{Sc}$, As, и Ac [9]. По данным самолетных измерений [13] вертикальная мощность St и Sc колеблется от 0,2 до 0,8 км, As и Ac - от 0,2 до 2 км (табл. 1), а горизонтальная протяженность этих систем - от сотен до тысячи километров [9].

Неустойчивая воздушная масса характеризуется облаками $\mathrm{Cu}$-Cong и $\mathrm{Cb}$ [9]. Их вертикальные мощности соответственно изменяется от 0,2 до 4,0 км и от 3 до 5-7 км и более [13], а горизонтальная протяженность - от нескольких километров до нескольких десятков километров [9]. Из Сb отмечаются выпадение кратковременных ливневых осадков и града, сопровождающихся грозоградовыми процессами и шквалистыми усилениями ветра.

В теплый период года:

теплые фронты характеризуются облачной системой As-

$\mathrm{Sc}-\mathrm{Ns}$ и обуславливают выпадение обложных осадков [9],

ТабЛИца 1. ЗНАЧЕНИЯ ПАРАМЕТРОВ ПООС ПО ДАННЫМ НАЗЕМНОЙ МЕТЕОРОЛОГИЧЕСКОЙ СТАНЦИИ (НМС) И САМОЛЕТА-МЕТЕОЛАБОРАТОРИИ (СМЛ)

\begin{tabular}{|c|c|c|c|c|}
\hline \multirow[t]{2}{*}{ Параметры ПООС } & \multicolumn{4}{|l|}{ Классы ПООС } \\
\hline & St, Sc & Ns & As, Ac & $\mathrm{Ci}, \mathrm{Cs}, \mathrm{Cc}$ \\
\hline$H_{\mathrm{H},}, \mathrm{KM}$ & $0.2 \div 1.5$ & $0.1 \div 1.0$ & $2.0 \div 5.0$ & $4.0 \div 11.0$ \\
\hline$\overline{H_{\mathrm{B}}, \mathrm{KM}}$ & $0.6 \div 2.8$ & $0.6 \div 2.8$ & $2.2 \div 6.0$ & $6.0 \div 13.0$ \\
\hline$\Delta H$, км & $0.2 \div 0.8$ & $2.0 \div 5,0$ & $0.2 \div 2.0$ & $0.1 \div 5.0$ \\
\hline$t_{\mathrm{Hr},}{ }^{\circ} \mathrm{C}$ & $10 \div-4$ & $10 \div-8$ & $3 \div-20$ & $-12 \div-70$ \\
\hline$t_{\mathrm{B}},{ }^{\circ} \mathrm{C}$ & $6 \div-8$ & $8 \div-11$ & $-1 \div-26$ & $-25 \div-75$ \\
\hline Фазовое состояние & Капельное & Смешанное & Смешанное & Кристаллическое \\
\hline$W, \mathrm{~m} / \mathrm{c}$ & $0.01 \div 0.2$ & $0.01 \div 0.2$ & $0.02 \div 0.2$ & - \\
\hline$V_{\Gamma}, M / c$ & - & - & - & - \\
\hline$d_{\mathrm{kP}}, \mathrm{MKM}$ & - & - & - & - \\
\hline$\overline{\sigma_{w}, \mathrm{M} / \mathrm{C}}$ & $0.1 \div 0.3$ & $0.1 \div 0.5$ & $0.1 \div 0.9$ & $0.1 \div 0.7$ \\
\hline$L_{T}, \mathrm{KM}$ & 20 & 20 & $10 \div 70$ & $10 \div 80$ \\
\hline$\Delta \varepsilon, \mathrm{CM}^{2} / \mathrm{c}^{3}$ & $8 \div 30$ & $8 \div 30$ & $8 \div 30$ & $1 \div 7$ \\
\hline $\bar{K}, \mathrm{~m}^{2} / \mathrm{c}$ & $20 \div 25$ & $3 \div 10$ & $3 \div 10$ & $3 \div 10$ \\
\hline$q, \Gamma / \mathrm{M}^{3}$ & $0.12 \div 0.27$ & $0.15 \div 0.33$ & $0.15 \div 0.21$ & 0.001 \\
\hline$P, \mathrm{~K} \Gamma / \mathrm{M}^{2}$ & $0.02 \div 0.28$ & $0.02 \div 0.56$ & $0.03 \div 0.4$ & 0.0001 \\
\hline
\end{tabular}


а при значительной влажности и неустойчивости воздушной массы формируются $\mathrm{Cb}$, сопровождающихся кратковременным увеличением интенсивности осадков;

холодные быстродвижущиеся фронты характеризуются облачной системой $\mathrm{As}-\mathrm{Ac}-\mathrm{Cb}$, а медленно движущиеся фронты - облачной системой $\mathrm{Ns}-\mathrm{As}-\mathrm{Cb}$ [9];

фронты окклюзии характеризуются сложным сочетанием холодных и теплых фронтов, которые, в зависимости от соотношения их масс и направлсния перемещения, развиваются по типу холодного и/или теплого фронтов [9]. Длина облачных систем фронтального происхождения составляет тысячи и более километров, а ширина - сотни километров [9]. В переходные периоды из $\mathrm{Ns}$-As выпадают обложные осадки слабой и умеренной интенсивности. Иногда внутри них, в виде «затопленных» конвективных образований, отмечаются облака вертикального развития сравнительно малой мощности (Cu, $\mathrm{Cu}-\mathrm{Cong})$, которые играют важную роль в формировании как естественных, так и искусственных осадков. При воздействии происходит перерастание $\mathrm{Cu}-\mathrm{Cong}$ в $\mathrm{Cb}$, а, следовательно, увеличение из них искусственных осадков.

Table 1. The values of the parameters of clouds and cloud systems fields (CCSF) according to meteorological earth station (MES) and airplane data

\begin{tabular}{llllll}
\hline Cu-Cong & Cb & As-Ac-Cb & Ns-As-Cb & Ns-As \\
\hline $1.0 \div 1.5$ & $1.5 \div 2.0$ & $1.0 \div 2.0$ & $0.1 \div 1.0$ & $0.1 \div 1.0$ \\
\hline $1.2 \div 6.0$ & $4.0 \div 13.0$ & $5.0 \div 13.0$ & $6.0 \div 13.0$ & $5.0 \div 6.0$ \\
\hline $0.2 \div 4.0$ & $3.0 \div 5.7$ & $2.0 \div 5.0$ & $2.0 \div 5.7$ & $2.0 \div 5.0$ \\
\hline $19 \div 1$ & $15 \div 6$ & $20 \div 10$ & $17 \div 10$ & $26 \div 8$ \\
\hline$-4 \div-20$ & $-5 \div-25$ & $-1 \div-26$ & $-10 \div-25$ & -18 \\
\hline смешанное & Смешанное & Смешанное & Смешанное & Смешанное \\
\hline $2.0 \div 12.0$ & $2.0 \div 50.0$ & $2 \div 40.0$ & $0.08 \div 1.0$ & $0.02 \div 0.2$ \\
\hline $1-2$ & $1-4$ & $1-4$ & $1-3$ & $0.1-1.0$ \\
\hline 5500 & $\leq 1000$ & $\leq 800$ & 5700 & $\leq 200$ \\
\hline $1.0 \div 2.0$ & $1.0 \div 20$ & $0.1 \div 2.8$ & $0.2 \div 1.6$ & $0.1 \div 0.3$ \\
\hline $10 \div 70$ & 20 & $10 \div 40$ & $10 \div 50$ & $10 \div 70$ \\
\hline $50 \div 300$ & $200 \div 1000$ & $5 \div 6$ & $20 \div 100$ & $1 \div 5$ \\
\hline $10 \div 300$ & $200 \div 500$ & $150 \div 300$ & $50 \div 100$ & $13 \div 15$ \\
\hline $0.06 \div 1.2$ & $0.9 \div 1.7$ & $0.15 \div 0.97$ & $0.13 \div 0.75$ & $0.15 \div 0.27$ \\
\hline $0.01 \div 4.8$ & $2.7 \div 9.5$ & $2.2 \div 5.3$ & $0.02 \div 0.41$ & $0.02 \div 0.48$ \\
\hline
\end{tabular}


3.

Особенности генетико-морфологической классификации ПООС по данным дистанционных методов наблюдений

Радиолокационные методы исследования способствовали созданию новой радиолокационной классификации ПООС, связанной с общепринятой генетико-морфологической классификацией. Она основана на качественных признаках вертикального и горизонтального распределения радиоэха облачности и ее количественных характеристиках, включающих в себя:

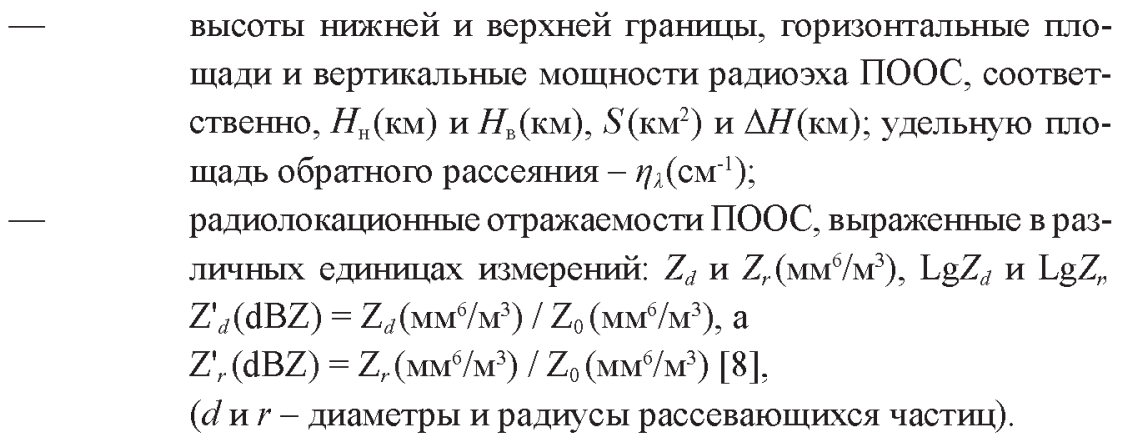

Перечисленные выше параметры, с различными размерностями, часто используются в литературных источниках и научных отчетах различных регионов мира для оценки: физической и экономической эффективности работ по ПГЗ и ИУО; градоопасности ЗТ и прилегающих территории (ПТ). Однако их сравнительная оценка между собой часто затруднена. В связи с этим получена таблица 2, связывающая между собой выше перечисленные параметры с различными размерностями и позволяющая переводить значения $\eta_{\lambda i}$ в значения $\operatorname{Lg} Z$ и $Z^{\prime}$ и обратно [8].

Таблица 2. Соотношения между значениями $\eta_{\lambda i}\left(\mathrm{CM}^{-1}\right), \operatorname{Lg} Z$ С $Z^{\prime}(\mathrm{dBZ})$ [8] Table 2. The correlations between the values of $\eta_{\lambda j}\left(\mathrm{CM}^{-1}\right), \operatorname{Lg} Z$ AND $Z^{\prime}(\mathrm{dBZ})[8]$

\begin{tabular}{|c|c|c|c|c|c|c|c|}
\hline 1 & 2 & 3 & 4 & 5 & 6 & 7 & 8 \\
\hline$\eta_{3.2}, \mathrm{CM}^{-1}$ & $1 \cdot 10^{-11}$ & $5 \cdot 10^{-11}$ & $1 \cdot 10^{-10}$ & $5 \cdot 10^{-10}$ & $1 \cdot 10^{-9}$ & $5 \cdot 10^{9}$ & $1 \cdot 10^{-8}$ \\
\hline$\eta_{5.6}, \mathrm{CM}^{-1}$ & $1 \cdot 10^{-12}$ & $5 \cdot 10^{-12}$ & $1 \cdot 10^{-11}$ & $5 \cdot 10^{-11}$ & $1 \cdot 10^{-10}$ & $5 \cdot 10^{10}$ & $1 \cdot 10^{-9}$ \\
\hline$\eta_{10}, \mathrm{CM}^{-1}$ & $1 \cdot 10^{-13}$ & $5 \cdot 10^{-13}$ & $1 \cdot 10^{-2}$ & $5 \cdot 10^{-12}$ & $1 \cdot 10^{-11}$ & $5 \cdot 10^{11}$ & $1 \cdot 10^{-10}$ \\
\hline $\operatorname{Lg} \bar{Z}_{d}$ & 0.5 & 1.2 & 1.5 & 2.2 & 2.5 & 3.2 & 3.5 \\
\hline$L g Z_{r}$ & -1.3 & -0.6 & -0.3 & 0.4 & 0.7 & 1.4 & 1.7 \\
\hline$Z_{d}^{\prime}(\mathrm{dBZ})$ & 5 & 12 & 15 & 22 & 25 & 32 & 35 \\
\hline$Z_{r}^{\prime}(\mathrm{dBZ})$ & -13 & -6 & -3 & 4 & 7 & 14 & 17 \\
\hline
\end{tabular}




\begin{tabular}{|c|c|c|c|c|c|c|c|}
\hline$\overline{1}$ & 9 & 10 & 11 & 12 & 13 & 14 & 15 \\
\hline$\overline{\eta_{3.2}, \mathrm{~cm}^{-1}}$ & $5 \cdot 10^{-8}$ & $1 \cdot 10^{-7}$ & $5 \cdot 10^{-7}$ & $1 \cdot 10^{-6}$ & $5 \cdot 10^{-6}$ & $1 \cdot 10^{-5}$ & $5 \cdot 10^{-5}$ \\
\hline$\overline{\eta_{3.2}, \mathrm{~cm}^{-1}}$ & $5 \cdot 10^{-9}$ & $1 \cdot 10^{-8}$ & $5 \cdot 10^{-8}$ & $1 \cdot 10^{-7}$ & $5 \cdot 10^{-7}$ & $1 \cdot 10^{-6}$ & $5 \cdot 10^{-6}$ \\
\hline$\eta_{5.6}, \mathrm{CM}^{-1}$ & $5 \cdot 10^{-10}$ & $1 \cdot 10^{-9}$ & $5 \cdot 10^{-9}$ & $1 \cdot 10^{-8}$ & $5 \cdot 10^{-8}$ & $1 \cdot 10^{-7}$ & $5 \cdot 10^{-7}$ \\
\hline $\operatorname{Lg} Z_{d}$ & 4.2 & 4.5 & 5.2 & 5.5 & 6.2 & 6.5 & 7.2 \\
\hline $\operatorname{Lg} Z_{r}$ & 2.4 & 2.7 & 3.4 & 3.7 & 4.4 & 4.7 & 5.4 \\
\hline$\overline{Z_{d}^{\prime}(\mathrm{dBZ})}$ & 42 & 45 & 52 & 55 & 62 & 65 & 72 \\
\hline$Z_{r}^{\prime}(\mathrm{dBZ})$ & 24 & 27 & 34 & 37 & 44 & 47 & 54 \\
\hline
\end{tabular}

\section{Радиоэхо облачности ниюснего яруса $(\mathrm{St}, \mathrm{Sc})$}

На индикаторе дальность-высота (ИДВ) МРЛ она характеризуется однородной по вертикали микроструктурой, так как не содержат мелкие частицы и фазовый состав сравнительно однороден (табл. 3), а на индикаторе кругового обзора (ИКО) МРЛ - в виде сплошной полосы, которая для $\mathrm{Sc}$ по мере удаления от МРЛ приобретает ячеистую структуру. Для St и $\mathrm{Sc}$ диапазоны вероятных значений высот нижней $\left(H_{\mathrm{H}}\right)$ и верхней $\left(H_{\mathrm{B}}\right)$ границы радиоэха ПООС и их отражаемости $\left(Z^{\prime}\right)$ изменяются соответственно от 0,1 до 1,5 км, от 0,8 до 2,3 км и $<18 \mathrm{dBZ}$.

\section{Радиоэхо слоисто-дождевой облачности нижнего яруса}

На ИДВ МРЛ она характеризуется четко выраженным максимумом отражаемости (яркой полосой) в области изотермы $0^{\circ} \mathrm{C}$, формирующейся за счет различия радиолокационной отражаемости воды и льда, а также концентрации частиц ниже и выше уровня изотермы $0^{\circ} \mathrm{C}$ (табл. 3). На ИКО МРЛ она занимает большие площади и имеет более или менее однородную структуру отражаемости.

\section{Радиоэхо облачности среднего яруса (As, $A$ )}

На ИДВ МРЛ она характеризуется некоторым увеличением отражаемости в ее средней части, обусловленной наличием крупных частищ (табл. 3). На ИКО МРЛ радиоэхо этой облачности просматривается в виде сплошной полосы, которое для Ас по мере удаления от МРЛ приобретает ячеистую структуру с параметрами $H_{\mathrm{H}}=2.5-5.0 \mathrm{\kappa м}, H_{\mathrm{B}}=3.5-7.0 \mathrm{\kappa м}$, $Z^{\prime}=12-30 \mathrm{dBZ}$. 


\section{Радиоэхо облачности верхнего яруса (Ci, Cs)}

Она характеризуются следующими значениями:

$H_{\mathrm{II}}=5-7 \mathrm{\kappa м}$;

$H_{\mathrm{B}}=6-10$ км и

$\mathrm{Z}^{\prime}=12-18 \mathrm{dBZ}$ (табл. 3).

В ближней зоне радиолокационная классификация отдельных типов облаков осушествляется [14] детерминированным описанием их радиолокационных характеристик, а дальней зоне - особенностями их распределения в пространстве. Существование связей между геометрическими размерами облаков и размерами их радиоэха на ИКО, а также между микроструктурой облаков и интенсивностью радиоэха дает основание использовать особенности пространственного распределения радиолокационных характеристик для определения класса ПООС. Они предусматривают распределение радиоэха по площади, наблюдаемое на ИКО МРЛ; пространственное распределение высоты верхней границы радиоэха и отражаемости на наиболее характерном уровне, расположенном на 2 км выше нулевой изотермы, представленные в виде карты. Радиолокационные наблюдения за ПООС позволили классифицировать основные типы облачных систем по указанным радиолокационным признакам.

\section{Радиоэхо облачности вертикального развития}

На ИДВ МРЛ радиоэхо облачности $\mathrm{Cu}-\mathrm{Cong}$ и $\mathrm{Cb}$ характеризуется следующими особенностями (рис. 1 , рис. 2 , табл. 3): имеет выраженный максимум радиолокационной отражаемости $\left(Z_{n \prime}^{\prime}\right)$ и высота расположения $Z_{m}^{\prime}$ зависит от стадии ее развития. Рассмотренные особенности радиоэха

Pис. 1.

Радиоэхо облачной системы типа Cu-Cong.

Fig. 1. Radio echo of the Cu-Cong type cloud system.

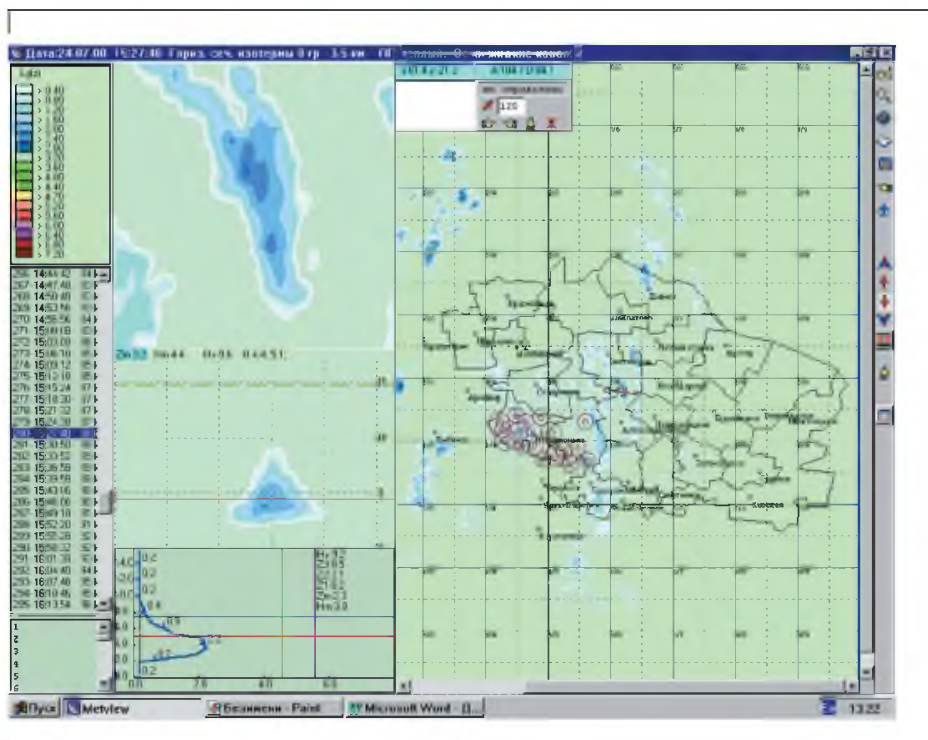




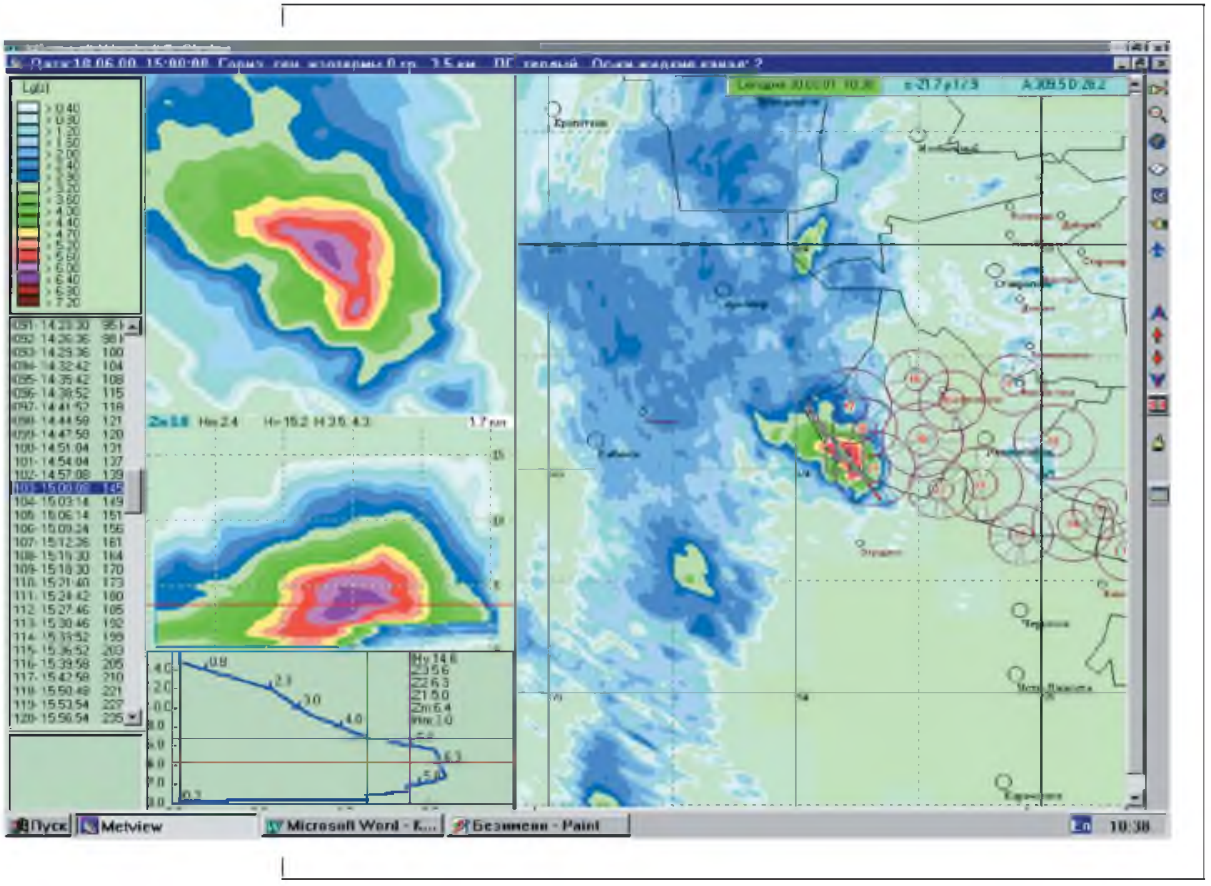

Рис. 2.

Радиоэхо облачной системы типа $\mathrm{Cb}$.

Fig. 2. Radio echo of the $\mathrm{Cb}$ type cloud system.

ПООС, характер их распределения на ИКО и ИДВ (табл. 3, рис. 1, рис. 2) хорошо просматриваются на мониторе ЭВМ МРЛ.

Методика индикации $\mathrm{Cu}$-Cong и $\mathrm{Cb}$ основана на определении вероятности принадлежности конвективной облачности к классу мощно-кучевых или кучево-дождевых облаков.

\section{Радиозхо слоисто-кучево-дожсевой облачности $(A s-A c-C b)$}

На ИКО МРЛ радиоэхо имеет вид полосы или нескольких полос (рис. 3, табл. 3). В теплый период года система связана с быстродвижущимися атмосферными фронтами и представляет собой гряду кучево-дождевых облаков, сопровождаемую облаками среднего яруса As и Ac. Конвективные облака, наблюдаемые в облачной системе, находятся в различных стадиях развития, что способствует неоднородному характеру распределения на ИКО и ИДВ МРЛ высот верхней границы радиоэха облачности $\left(H_{\mathrm{B}}=5-13\right.$ км) и ее радиолокационной отражаемости $\left(Z^{\prime}=28-68 \mathrm{dBZ}\right)$; а, следовательно, выпадению осадков различной интенсивности: умеренных $(3.0-25.0 \mathrm{Mm} /$ ч) при $Z^{\prime}=30-45 \mathrm{dBZ}$; сильных (25.1 - 140.0 мм/ч) при $Z^{\prime}=46-57 \mathrm{dBZ}$; очень сильных (>140 мм/ч) при $Z^{\prime}>57 \mathrm{dBZ}$. 
Рис. 3.Радиоэхо облачной системы типа As-Ac-Cb.

Fig. 3. Radio echo of the As-Ac-Cb type cloud system.

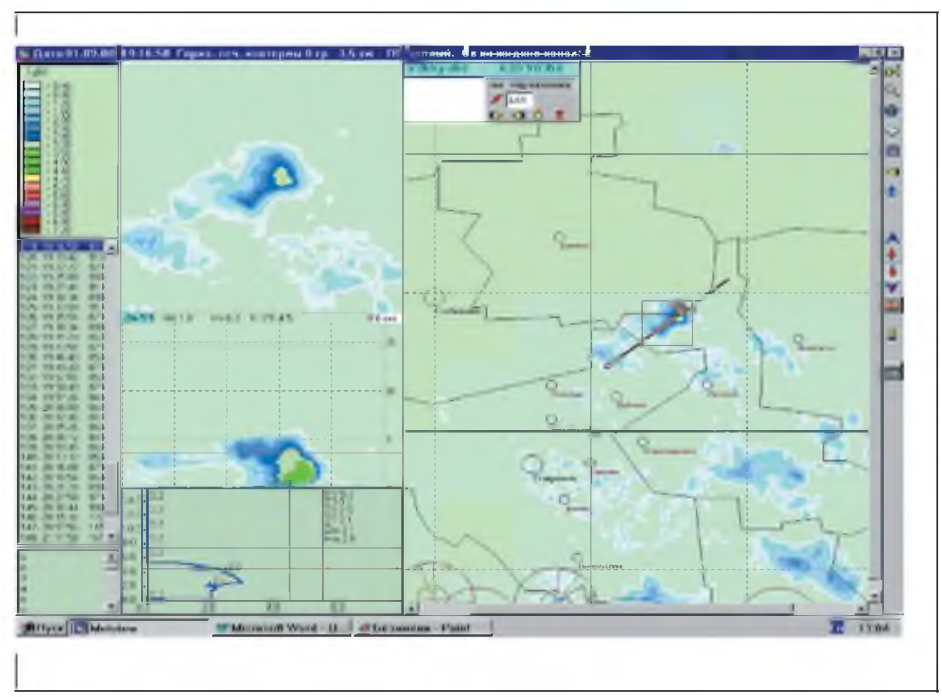

Радиоэхо слоисто-кучево-дождевой облачности $(\mathrm{As}-\mathrm{Ns}-\mathrm{Cb})$

На ИКО МРЛ радиоэхо представляет собой сплошную область без резко очерченных границ, которое по мере увеличения расстояния от МРЛ переходит в отдельные полосы или ячейки (рис. 4, табл. 3).

Распределение высот верхней границы радиоэха $\mathrm{Cb}$ в целом определяется интенсивностью конвекции. При слабой конвекции верхняя граница $\mathrm{Cb}$ располагается на одинаковой высоте с облачной системой (затопленные конвективные образования), а по мере увеличения расстояния от МРЛ монотонно уменьшается. При формировании кучево-дождевой облачности в области отрицательных температур на одинаковых расстояниях от МРЛ наблюдается неоднородное поле высоты верхней границы радиоэха и отражаемости.

Pис. 4.

Радиоэхо облачной системы типа As-Ns-Cb.

Fig. 4. Radio echo of the As-Ns-Cb type cloud system.

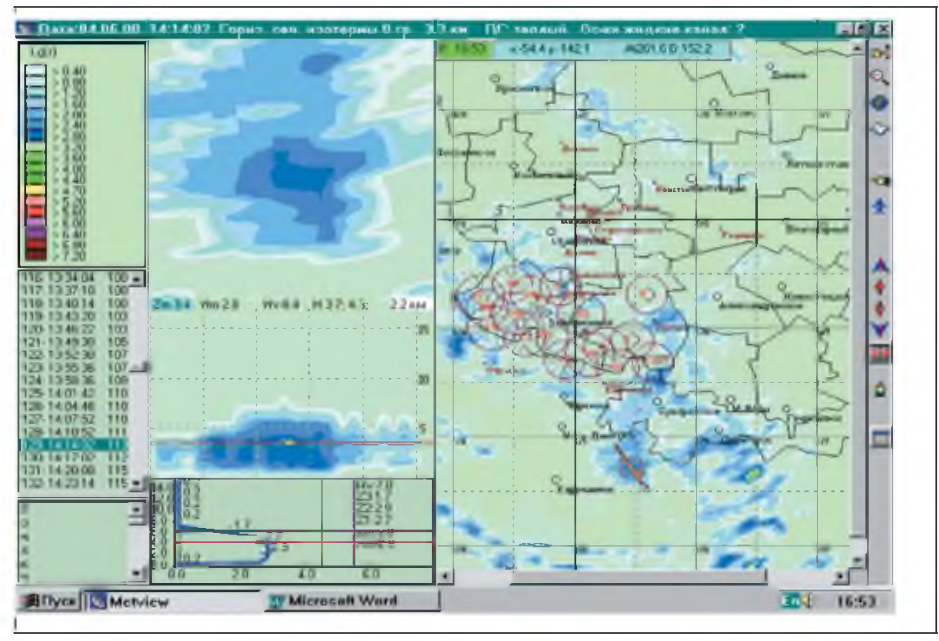


При слабой конвекции система As-Ns Cb проявляет особенности облачной системы As-Ns, a при сильной конвекции - особенности облачной системы $\mathrm{Cb}-\mathrm{Ac}$.

Oб̆ачная система слоистых фори (As Ns)

На ИКО МРЛ она представляет собой сплошное радиоэхо слоистообразной облачности без резко очерченных границ (рис. 5, табл. 3). Она связана с атмосферными фронтами и простирается до нескольких сот километров. На ИДВ МРЛ высоты верхней границы радиоэха этой системы на одинаковых расстояниях от МРЛ практически одинаковы, а с удалением монотонно уменьшаются.

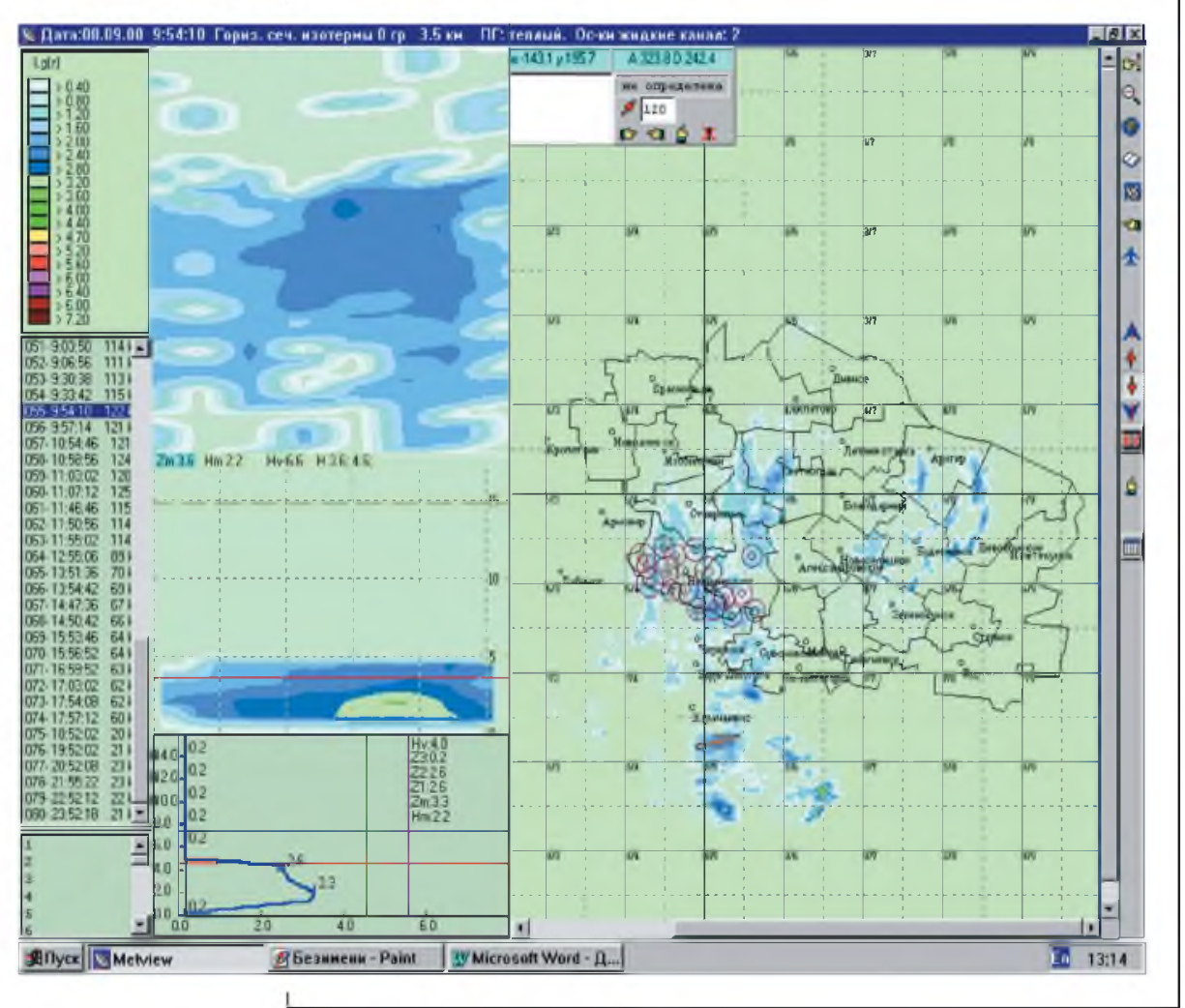

Рис. 5. Радиоэхо облачной системы типа As-Ns.

Fig. 5. Radio echo of the As-Ns type cloud system.

Развитие системы сопровождается выпадением обложных осадков слабой интенсивности $I=0.5-2.8 \mathrm{Mm} /$ ч, которым соответствуют значения

$$
H_{\mathrm{s}}=3-9 \text { км и } Z^{\prime}=18-20 \mathrm{dBZ} .
$$


Table 3. The values of the ccsf parametes according to meteorological radar (MR) data

\begin{tabular}{|c|c|c|c|c|}
\hline \multirow{2}{*}{$\begin{array}{l}\text { Параметры } \\
\text { облака }\end{array}$} & \multicolumn{4}{|l|}{ Классы ПООС } \\
\hline & 2 & 3 & 4 & 5 \\
\hline 1 & St, Sc & Ns & As, Ac & $\mathrm{Ci}, \mathrm{Cs}, \mathrm{Cc}$ \\
\hline$H_{\mathrm{H} r}, \mathrm{KM}$ & $0.1 \div 1.5$ & $0.1 \div 1.0$ & $2.5 \div 5.0$ & $5.0 \div 7.0$ \\
\hline$H_{\mathrm{B}}, \mathrm{KM}$ & $0.8 \div-2.3$ & $0.6 \div 2.8$ & $3.5 \div 7.0$ & $6.0 \div 10.0$ \\
\hline$\Delta H, \mathrm{KM}$ & $0.7 \div-0.8$ & $2.0 \div 5.0$ & $1.0 \div 2.0$ & $1.0 \div 3.0$ \\
\hline$t_{\mathrm{H},}{ }^{\circ} \mathrm{C}$ & $10 \div-4$ & $10 \div-8$ & $3 \div-20$ & $-12 \div-70$ \\
\hline$t_{\mathrm{B}},{ }^{\circ} \mathrm{C}$ & $6 \div-8$ & $8 \div-11$ & $-1 \div-26$ & $-25 \div-75$ \\
\hline Фазовое состояние & Капельное & Смешанное & Смешанное & Кристаллическое \\
\hline $\begin{array}{l}\text { Характер } \\
\text { распределения } \\
\text { радиоэха } \\
\text { по площади }\end{array}$ & $\begin{array}{l}\text { Однородное } \\
\text { поле, с удале- } \\
\text { нием от МРЛ } \\
\text { Sс принимают } \\
\text { ячеистую } \\
\text { структуру }\end{array}$ & $\begin{array}{l}\text { Одно- } \\
\text { родное } \\
\text { поле }\end{array}$ & $\begin{array}{l}\text { На ИДВ } \\
\text { увеличение } \\
\text { Z' в средней } \\
\text { части за счет } \\
\text { крупных } \\
\text { частиц }\end{array}$ & $\begin{array}{l}\text { Радиоэхо в виде } \\
\text { сплошной полосы }\end{array}$ \\
\hline $\begin{array}{l}\text { Характер } \\
\text { распределения } \\
\text { высоты } \\
\text { радиоэха }\end{array}$ & $\begin{array}{l}\text { Незначи- } \\
\text { тельные } \\
\text { изменения } \\
\text { с высотой }\end{array}$ & $\begin{array}{l}\text { Яркая } \\
\text { полоса } \\
\text { в области } \\
\text { изотермы } \\
0^{\circ} \mathrm{C}\end{array}$ & $\begin{array}{l}\text { Ас с удале- } \\
\text { ния от МРЛ } \\
\text { принимают } \\
\text { ячеистую } \\
\text { структуру }\end{array}$ & $\begin{array}{l}\text { Полоса с игольчатой } \\
\text { структурой }\end{array}$ \\
\hline $\begin{array}{l}\text { Диапазон зна- } \\
\text { чений Z' dBZ, } \\
\text { явление }\end{array}$ & $\begin{array}{l}<18, \text { без } \\
\text { осадков }\end{array}$ & $12-33$ & $12-32$ & $12-18$ \\
\hline
\end{tabular}

\begin{tabular}{|c|c|c|c|c|c|}
\hline \multirow{2}{*}{1} & 6 & 7 & 8 & 9 & 10 \\
\hline & Cu-Cong & $\mathrm{Cb}$ & $A s-A c-C b$ & As-Ns-Cb & As-Ns \\
\hline$H_{\mathrm{Hr}}, \mathrm{KM}$ & $1.0 \div 1.5$ & $1.5 \div 2.0$ & $1.0 \div 2.0$ & $0.1 \div 1.0$ & От земли \\
\hline$\overline{H_{\mathrm{B}}, \mathrm{KM}}$ & $1.2 \div 6.0$ & $5.0 \div 15.0$ & $5.0 \div 13$ & $5.0 \div 13.0$ & $3.0 \div 9.0$ \\
\hline$\Delta H, \mathrm{kM}$ & $0.6 \div 5.5$ & $3.0 \div 5.7$ & $2.0 \div 5.0$ & $4.9 \div 12.0$ & $2.0 \div 5.0$ \\
\hline$t_{\mathrm{Hr},}{ }^{\circ} \mathrm{C}$ & $19 \div 1$ & $15 \div 6$ & $20 \div 10$ & $15 \div 10$ & $26 \div 8$ \\
\hline$t_{\mathrm{B}},{ }^{\circ} \mathrm{C}$ & $-4 \div-20$ & $-5 \div-25$ & $-1 \div-26$ & $-10 \div-75$ & -18 \\
\hline Фазовое состояние & Смешанное & Смешанное & Смешанное & Смешанное & Смешанное \\
\hline $\begin{array}{l}\text { Характер } \\
\text { распределения } \\
\text { радиоэха } \\
\text { по площади }\end{array}$ & $\begin{array}{l}\text { Хаотически } \\
\text { разбро- } \\
\text { санные } \\
\text { ячейки }\end{array}$ & $\begin{array}{l}\text { Хаотически } \\
\text { разбро- } \\
\text { санные } \\
\text { ячейки }\end{array}$ & $\begin{array}{l}\text { Полосы } \\
\text { или } \\
\text { несколько } \\
\text { полос }\end{array}$ & $\begin{array}{l}\text { Неоднород- } \\
\text { ное поле с } \\
\text { отдельными } \\
\text { полосами }\end{array}$ & $\begin{array}{l}\text { Одно- } \\
\text { родное } \\
\text { поле }\end{array}$ \\
\hline $\begin{array}{l}\text { Характер } \\
\text { распределения } \\
\text { высоты } \\
\text { радиоэха }\end{array}$ & $\begin{array}{l}\text { Неодно- } \\
\text { родное поле }\end{array}$ & $\begin{array}{l}\text { Неодно- } \\
\text { родное } \\
\text { поле }\end{array}$ & $\begin{array}{l}\text { Неоднород- } \\
\text { ное поле на } \\
\text { одинаковых } \\
\text { расстояниях }\end{array}$ & $\begin{array}{l}\text { Неодно- } \\
\text { родное } \\
\text { поле }\end{array}$ & $\begin{array}{l}\text { С увели- } \\
\text { чением } \\
\text { расстояния } \\
\text { Нв умень- } \\
\text { шается }\end{array}$ \\
\hline $\begin{array}{l}\text { Диапазон } \\
\text { значений Z' dBZ, } \\
\text { явление }\end{array}$ & $\begin{array}{l}\text { 4-36, без } \\
\text { осадков }\end{array}$ & $\begin{array}{l}\text { 19-68, } \\
\text { ливень, } \\
\text { град, шквал }\end{array}$ & $\begin{array}{l}\text { 28-68, } \\
\text { ливень, } \\
\text { град, шквал }\end{array}$ & $\begin{array}{l}\text { 28-68, } \\
\text { ливень, } \\
\text { град, шквал }\end{array}$ & $\begin{array}{l}\text { 8-28, } \\
\text { слабые } \\
\text { осадки }\end{array}$ \\
\hline
\end{tabular}




\section{4. Типы градовых процессов в ПООС}

Значения характеристик параметров ПООС и характер их распределения в атмосфере, полученные по данным МРЛ и аэросиноптических материалов, позволили в реальном масштабе времени выявить наблюдаемые типы градовых процессов (ГП). Они, в зависимости от структуры и динамики развития, направления и скорости перемещения воздушных масс по высотам, были разделены на: одноячейковые, многоячейковые (упорядоченные, неупорядоченные, и слабоорганизованные) и суперячейковые процессы. Физические условия формирования типов градовых процессов изложены в работах $[1,20]$.

\section{5. Критерии засева ОВ 1-4-й категории в ПООС}

Радиолокационный метод оценки интенсивности развития OB 1-2-й и 3-4-й категорий основан на использовании комплекса радиолокационных и физических параметров ПООС, включающего в себя мощности $\left(\Delta H_{45}\right.$, км) и площади горизонтального сечения переохлажденной части конвективной ячейки - КЯ $\left(\Delta S_{45}\right.$, км$\left.^{2}\right)$ ограниченных изоконтурами радиолокационной отражаемости $Z_{d}^{\prime}=45 \mathrm{dBZ}$ Сопоставление значений указанных параметров с видом выпавших осадков позволило построить график (рис. 6), на котором с вероятностью 90\% были выделены области: с ливнями (I); слабыми и умеренными градобитиями (II); катастрофическими градобитиями (III).

Проверка полученного графика на независимом материале региона Центрального Кавказа, включающего в себя: Северо-Кавказскую ВС (СевКав. ВС), ВС Краснодарского края и Грузинского УГМ показала высокую его оправдываемость.

Критерии засева OB 1-4-й категорий представлены в табл. 4, где:

$\Delta H_{Z m},(\kappa м)$ - высота первого радиоэха в области отрицательных температур; $Z_{m}^{\prime}(\mathrm{dBZ})$ - максимальная радиолокационная отражаемость; $\Delta H_{35}$ и $\Delta H_{45}$ (км) - мощности зоны повышенной радиолокационной отражаемости в области отрицательных температур, соответственно ограниченные изоконтурами радиолокационной отражаемости $Z_{m}^{\prime}=35$ и $Z_{m}^{\prime}=45 \mathrm{dBZ}$.

Рис. 6. Связь интенсивности градового процесса с параметрами $\Delta S_{45}$ и $\Delta H_{45}$. Fig. 6. The connection of hailing rate with $\triangle S_{45}$ and $\Delta H_{45}$ data.

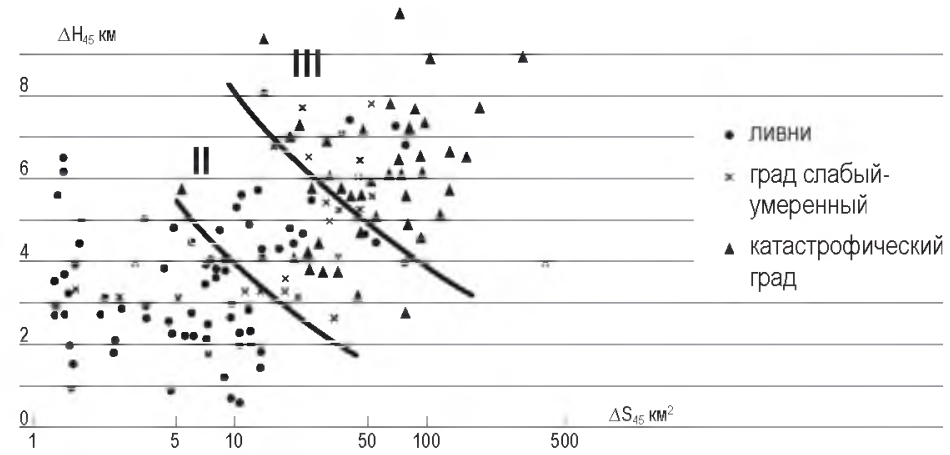


Недостатком действующих критериев засева ОВ 1-4-й категории является то, что при выявлении развивающихся ОВ 2-й категорий, характеризующихся параметрами $35<Z_{m}^{\prime}<55 \mathrm{dBZ}$ и $\Delta H_{35}<2.5$ км [1], не привлекался такой информативный параметр, как превышение высоты максимальной радиолокационной отражаемости $\left(\Delta H_{z m}\right.$, км $)$ над уровнем изотермы $0{ }^{\circ} \mathrm{C}\left(H_{0}\right.$, км) однозначно характеризующий их фазовую структуру [6]:

$$
\Delta H_{Z m}=H_{Z m}-H_{0}
$$

Если значения $Z_{m}$ в ОВ 2-й категорий фиксируются в теплой их части $\left(\Delta H_{Z m}<0\right)$, то они являются неградоопасными и воздействие на них не проводится; переохлажденной их части $\left(\Delta H_{Z m} \geq 0\right)$, то они, при естественном развитии с высокой вероятностью, могут перейти в OB 3-4-й категорий и подлежат немедленному воздействию [6].

Таблица 4. КРИТЕРИИ ЗАСЕВА ОВ 1-4-й КАТЕГОРИИ В ПООС [1]

Table 4. Seeding criteria of the object of effect of the 1st-4th category in CCSF [1]

\begin{tabular}{|c|c|c|c|c|}
\hline \multirow[t]{2}{*}{ Параметры ООС } & \multicolumn{4}{|l|}{ Категория ОВ } \\
\hline & $\overline{1}$ & 2 & 3 & 4 \\
\hline$\overline{Z_{m}^{\prime}}(\mathrm{dBZ})$ & $15<Z_{m}<35$ & $35 \leq Z_{m} \leq 55$ & $Z_{m}<55$ & $Z_{m}<65$ \\
\hline$\Delta H_{\Pi}(\mathrm{KM})$ & $1<\Delta H_{Z m}<4$ & $\Delta H_{35}>2.5$ & $\Delta H_{45}>3$ & $\Delta H_{45}>4$ \\
\hline
\end{tabular}

Параметр $\Delta H_{z m}$ дополнительно уточнялся и в зависимости от высоты расположения изотермы $0{ }^{\circ} \mathrm{C}$ над уровнем моря $\left(H_{0}\right)$. Воздействию подвергались все объекты 2-й категории, если:

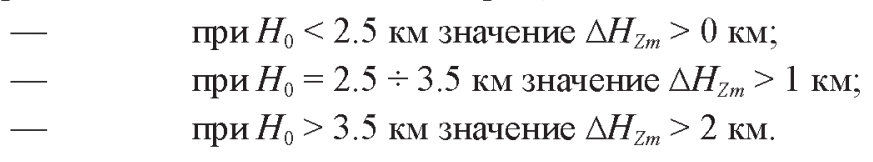

Совершенствованный критерий засева ОВ 2-й категорий может существенно повлиять на уменьшение количества: обработанных ячеек, израсходованных в них ПГР и затрат на их приобретение. Он в 2006-2007 гг. прошел апробацию на ЗТ ВС Ставропольского края [6].

Анализ материалов испытаний критериев засева ОВ 2-й категории в ПООС выявил, что в 2006 и 2007 г:

\footnotetext{
- $\quad$ воздействию подверглись 258 OB 2-й категорий с $\Delta H_{Z m} \geq 0$ и не подвергались воздействию 869 ОВ 2-й категорий со значениями параметра $\Delta H_{Z m}<0$; на обработку одного ОВ 2-й категории в среднем расходовалось 8 шт. ПГР «Алазань-6», стоимость одной из которой составляла 8 тыс. руб. по ценам 2006 и 2007 г.
} 
на обработку 869 шт. ОВ 2-й категории с $\Delta H_{Z m}<0$ потребовалось бы дополнительно израсходовать еще 6952 шт. «Алазань-6», что в денежном выражении составило 55 млн руб.

Таким образом, в Ставропольском крае средняя экономическая эффективность ПГЗ, достигающая в 2003-2007 гг. 360,1 млн рублей, была дополнительно увеличена еще на 55,6 млн руб. Совершенствованный критерий засева ОВ 2-й категории успешно внедрен в ПГЗ ВС Ставропольского края. Получен патент РФ на изобретение [4]

Радиолокационные параметры ПООС привлекались и для оценки нормы расхода количества ПГР «Алазань» и интенсивности стрельбы в объемах зон роста града и будущего градообразования градовых облаков. Оценка проводилась с помощью следующих уравнений [6]:

$$
\begin{aligned}
& n_{i} \approx 0.4 \Delta V_{45}, \\
& I_{i}=n_{i} / \Delta t_{\Phi} \approx 0.04 \Delta V_{45},
\end{aligned}
$$
где $n_{i}-\quad$ количество противоградовых ракет (ПГР) «А-6» шт., израс- ходованных на один ОВ;
$\Delta V_{45}-\quad$ объем зоны повышенного радиоэха, ограниченный изосфе- рой радиолокационной отражаемости $Z_{m}^{\prime}=45 \mathrm{dBZ}$;
$I_{i}-\quad$ скорострельность ПГР (шт./мин.);
$\Delta t_{\Phi}-\quad$ фактическая продолжительность воздействия на один ОВ 3-4-й (мин.), которая не должна превышать время градооб- разования в пространственно-фиксированном объеме гра- довых облаков, развивающихся в естественных условиях и при проведений на них активных воздействий.

Анализ полученных результатов, с применением уравнений (2) и (3) также показал увеличение как физической, так и экономической эффективности ПГЗ.

6.

\section{Критерии ИУО в ПООС [5, 6]}

Радиолокационными критериями ИУО из ПООС являются значения параметров, удовлетворяющим следующим условиям: $\eta_{m 3.2} \geq 10^{-11}$ $\mathrm{cm}^{-1}$ и/или $\operatorname{Lg} Z_{r} \approx 1.3, \Delta H_{\text {п }} \geq 1.5 \mathrm{\kappa м}, t_{\mathrm{H}_{\mathrm{B}}}<-10^{\circ} \mathrm{C}$. Они представлены табл. 5, где: $\eta_{m 3.2}\left(\mathrm{~cm}^{-1}\right)$ - максимальная удельная радиолокационная отражаемость в области отрицательных температур ПООС; $\Delta H_{\mathrm{B}}\left(\right.$ км) и $t_{\mathrm{H}_{\mathrm{B}}}\left({ }^{\circ} \mathrm{C}\right)$ - мощность переохлажденной части ПООС и температура на их верхней границе ПООС; $r$ (мкм) - радиус рассеивающих частиц при длине волны $\lambda=3.2 \mathrm{~cm}$. 
В литературных источниках в качестве критериев ОВ 1-4-й категорий (табл. 4) и ИУО (табл. 5) часто встречаются радиолокационные параметры отражаемости, имеющие и другие размерности: $\operatorname{Lg} Z_{d}, Z_{d}^{\prime}(\mathrm{dBZ}), Z_{r}^{\prime}(\mathrm{dBZ})$. Они все представлены в табл. 2 и позволяют оперативно перейти от одной размерности параметра радиолокационной отражаемости к другой и обратно.

Таблица 5. П ПАРАМЕТРЫ КРИТЕРИЕВ ИСКУССТВЕННОГО РЕГУЛИРОВАНИЯ ОСАДКОВ (ИРО) В ПООС

Table 5. The criteria parameters of artificial precipitation control (APC) in CCSF

\begin{tabular}{|c|c|c|c|c|c|}
\hline \multirow[t]{2}{*}{ Параметры ООС } & \multicolumn{5}{|c|}{ Классы ООС } \\
\hline & Cu-Cong & $\mathrm{Cb}$ & Ns-As-Cb & Ns-As-Ac & Ns-As \\
\hline$Z_{m}^{\prime}, \mathrm{dBZ}$ & $\geq 15$ & $\geq 15$ & $\geq 15$ & $\geq 15$ & $\geq 15$ \\
\hline$\Delta H_{n}, K M$ & $\geq 2.5$ & $\geq 2.0$ & $\geq 1.0$ & $\geq 3.0$ & 2.0 \\
\hline$t,{ }^{\circ} \mathrm{C}$ & $<-10$ & $<-10$ & $<-10$ & $<-10$ & $<-10$ \\
\hline
\end{tabular}

Метод индикации полей облачности основан на определении вероятности их принадлежности к одному из приведенных в табл. 4 классов.

На рисунке 7 представлен график зависимости вероятности формирования $\mathrm{Cu}$-Cong и $\mathrm{Cb}$ от значений радиолокационных и аэрологических параметров: $\eta_{m 3.2}$ и $\operatorname{Lg} Z_{m}, \Delta H_{\text {п }}$ и $t_{\mathrm{B}}$. На графике кривые вероятности индикации $\mathrm{Cu}-\mathrm{Cong}$ и Сb строились с учетом нелинейной связи между $\eta_{m}\left(\operatorname{Lg} Z_{m}\right)$ и $\Delta H_{\text {п }}\left(t_{H_{\mathrm{B}}}\right)[16]$.

Если на графике точка с координатами $\left(\eta_{m}, \Delta H_{\Pi}\right)$ попадает в область I, то с вероятностью $<50 \%$ индицируется $\mathrm{Cb}$, а если в II и III, то с вероятностью более $50 \%$ индицируется КЯ типа $\mathrm{Cb}$.

Воздействие в первом случае осушествляется на $\mathrm{Cu}$-Cong с целью стимулирования процесса осадкообразования; во втором случае - на $\mathrm{Cb}$ целью интенсификации процесса осадкообразования.

Приведенный на рис. 7 график может быть использован для определения возможности перерастания $\mathrm{Cu}-\mathrm{Cong}$ в стадию $\mathrm{Cb}$, если со временем точка с координатами $\left(\eta_{m}, \Delta H_{\text {п }}\right)$ будет попадать из области I в область II или III.
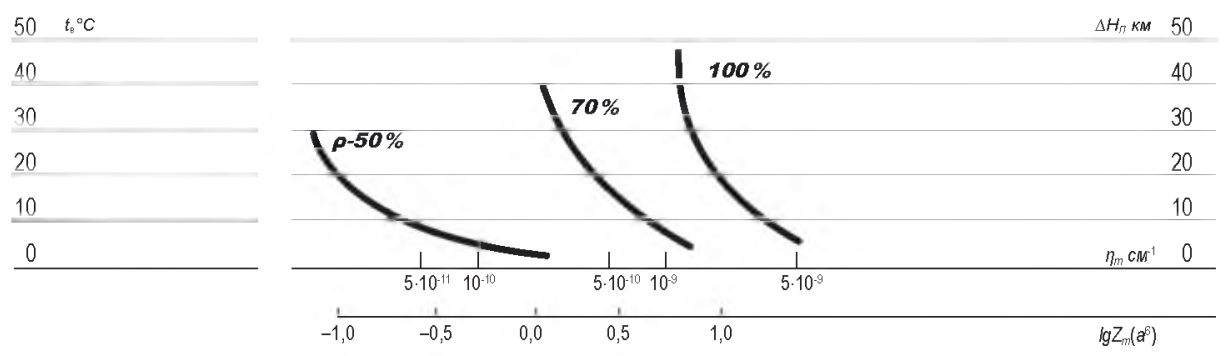

Рис. 7. Индикация Cu-Cong (I) и Сb (II) по данным МРЛ [16].

Fig. 7. The indication of $\mathrm{Cu}-\mathrm{Cong}(\mathrm{I})$ and $\mathrm{Cb}$ (II) according to MR data [16]. 
$\mathrm{Cu}-$ Cong и $\mathrm{Cb}$, подвергшиеся активному воздействия (AB), могут находиться на опытной территории (ОТ) или вне ее. В последнем случае по скорости и направлению перемещения определяется возможность их попадания на ОТ. Во всех случаях осадки из КЯ, подвергшихся воздействию должны выпасть на опытной территории (ОТ).

Нормы расхода количества противоградовых ракет «Алазань» в $\mathrm{Cu}$ Cong и $\mathrm{Cb}$, развивающихся в ПООС, рассчитываются в зависимости от значений радиолокационных и аэрологических параметров (рис. 8).

Пусть по данным МРЛ КЯ характеризуется следующими значениями параметров: $\eta_{m 3.2}=1 \cdot 10^{-9} \mathrm{~cm}^{-1}, \operatorname{Lg} Z_{m}\left(r^{6}\right)=0.7, \Delta H_{\text {п }}=3$ км и $t_{\mathrm{B}}=-15^{\circ} \mathrm{C}$. Согласно графику (рис. 7) мы попадаем в область, где с вероятностью более $70 \%$ отмечается развитие $\mathrm{Cb}$. В этом случае воздействие на $\mathrm{Cb}$ будет проводиться $\mathrm{c}$ целью интенсификации процесса осадкообразования с применением микрофизического засева $[5,6,7]$. Согласно приведенным радиолокационным данным и графика на рисунке 8 расход ПГР в точках пересечения значений координат этих параметров не превышает 3 шт. «Алазань».
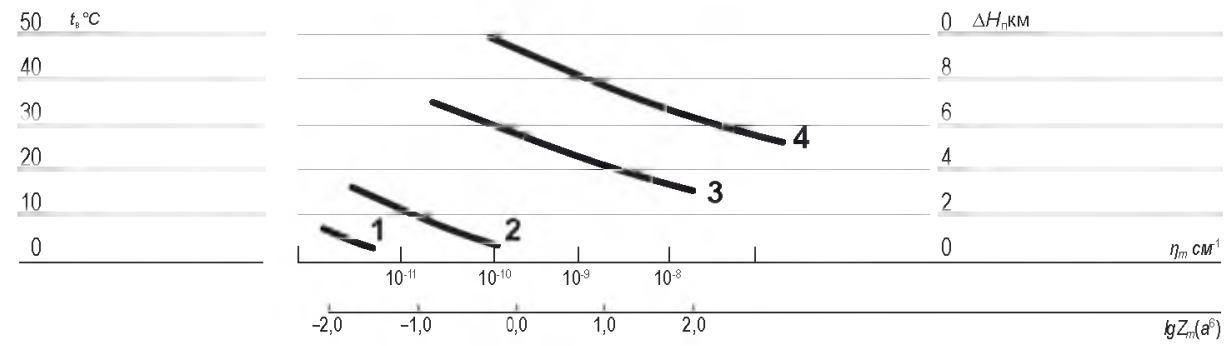

Рис. 8. Нормы расхода ПГР в КЯ в зависимости от значений $\eta_{m 3.2}$, $\mathrm{LgZ}_{m}, \Delta H_{n}$ и $t_{\mathrm{в}}(1-4-$ изолинии количества израсходованных ПГР на одну КЯ) [16].

Fig. 8. The consumption rate of AHR in convection cell (CC) depending on the values of $\eta_{m s, 2}, L g Z_{m}, \Delta H_{\mathrm{n}}$ and $t_{\mathrm{B}}(1-4-$ isometric lines of the AHR amount spent on one CC) [16].

\section{7. Критерии шквалов различной силы в ПООС}

Радиолокационные методы обнаружения шквалов со скоростью $15-25 \mathrm{~m} / \mathrm{c}$ и более разрабатывались с участием автора этой статьи. Они представлены в «Методических указаниях по определению шквалов с использованием данных МРЛ» [3] и руководящем документе «Руководство по производству наблюдений и применению информации с неавтоматизированных радиолокаторов МРЛ-1, МРЛ-2, и МРЛ-5 [14] и отличаются друг от друга в подходе к использованию аэрологических и синоптических данных в методах обнаружения шквалов. Они предназначены для диагноза и сверкраткосрочного прогноза скорости порывов ветра при шквале, связанных с развитием $\mathrm{Cb}$ в ПООС. Он предусматривает: 


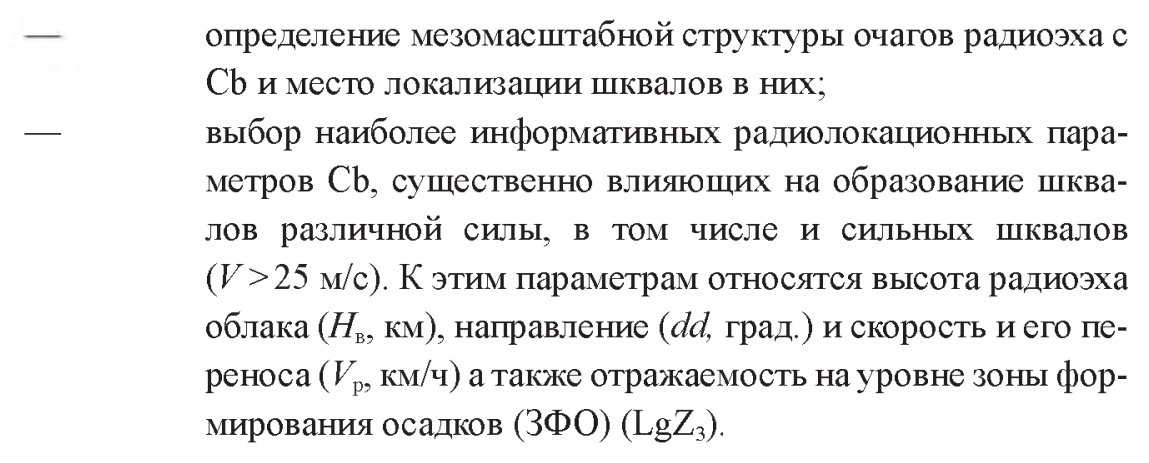

По данным МРЛ сильный шквал диагностируется при следующих значениях радиолокационных параметров: $H \geq 10$ км и $V_{\mathrm{p}} \geq 25$ км/ч. Заблаговременность радиолокационного метода диагноза и сверхкраткосрочного прогноза шквалов достигает 60 мин.

Аэросиноптико-радиолокационный метод [3, 14] отличается от радиолокационного метода дополнительным учетом аэрологических и синоптических данных для более надежного диагноза и сверхкраткосрочного прогноза фронтальных шквалов со скоростью более $25 \mathrm{M} / \mathrm{c}$.

Аэрологические данные, включают в себя: скорость восходящих движений в облаке $(W, \mathrm{M} / \mathrm{c})$, фазовый состав осадков, высоту тропопаузы $\left(H_{\mathrm{T}}, \mathrm{\kappa м}\right)$, температуру $\left(t_{\mathrm{B}},{ }^{\circ} \mathrm{C}\right)$ на высоте верхней границы радиоэха облака $(H$, км $)$ и разность этих высот $\left(H-H_{\mathrm{T}}\right.$, км).

Синоптические данные, включают в себя разности тенденции давления $\left(\Delta P\right.$, гПа/Зч) и контрасты температур $\left(\Delta T,{ }^{\circ} \mathrm{C}\right)$ на фронте.

Для диагноза сильных шквалов с $V \geq 25$ м/с построены графики, связывающие между собой параметры $V_{\mathrm{p}}$ и $U$ (рис. 9a), $\Delta P$ и $\Delta T$ (рис. 9б).

На оси ординат графика (рис. 9а) нанесены значения скорости переноса радиоэха облака $\left(V_{\mathrm{p}}\right)$, полученные по данным МРЛ, а на оси абцисс - значения дискриминантной функции $(U)$, рассчитанные по аэрологическим данным и данным МРЛ с помощью следующего уравнения:

$$
U=0.2 \lg Z_{3}+\left(H-H_{\mathrm{r}}\right)-0.1 t_{\mathrm{B}}
$$

$\triangle P$ рассчитывается, как максимальная разность тенденции падения и роста давления в пределах фронтального раздела длиной 500 км и шириной 300 км по направлению движения воздушных масс (рис. 10):

$$
\Delta P=\left(\Delta P_{1}-\Delta P_{2}\right), \Gamma \Pi а / 3 ч
$$

$\Delta T$ рассчитывается, как максимальная разность температур в пределах той же полосы (рис. 10): 


$$
\Delta T=T_{1}-T_{2},{ }^{\circ} \mathrm{C}
$$

Пусть в зоне холодного фронта (рис. 10) по данным МРЛ высота радиоэха $\mathrm{Cb} H=14 \mathrm{\kappa м}, \lg Z_{3}=2.4$ и $V_{\mathrm{p}}=40$ км/ч; по аэрологическим данным высота тропопаузы $H_{\mathrm{I}}=12 \mathrm{kм}$, температура на высоте верхней границы радиоэха $\mathrm{Cb} H_{\mathrm{r}}=57^{\circ} \mathrm{C}$; по синоптическим данным $\Delta P_{1}=1.5$ гПа $/ 3$ ч и $\Delta P_{2}=3.2$ гПа $/ 3$ ч; $T_{1}=26^{\circ} \mathrm{C}$ и $T_{2}=20^{\circ} \mathrm{C}$.

Диагноз сильного шквала выполняется в следующей последовательности.

С помощью уравнения (4) рассчитывается значение дискриминантной функции:

$$
U=0.2 \lg Z_{3}+\left(H-H_{\mathrm{T}}\right)-0.1 t_{\mathrm{B}}=0.2 \cdot 2.4+(14-12)-0.1 \cdot(-57) \approx 8.2 .
$$

По рассчитанному значению $U=8.2$ и измеренному с помощью МРЛ $V_{p}=40$ км/ч входим в график (рис. 9а). Если на графике точка с координатами $\left(U, V_{\mathrm{p}}\right)$ попадает ниже кривой линии «аa», то ставится диагноз «без сильного шквала», а если на линию «аа» или выше ее, то диагноз шквала уточняется с помощью рисунка 96. По значениям $\triangle P$ и $\triangle T$ уточняем диагноз сильного шквала. Если точка на рисунке 96 попадает выше или на линию «ббб», то диагностируется «сильный шквал», а если ниже и левее, то - отсутствие «сильного шквала». В заштрихованной зоне «сбб» шквал диагностируется при наличии грядовой структуры радиоэха облаков [3].
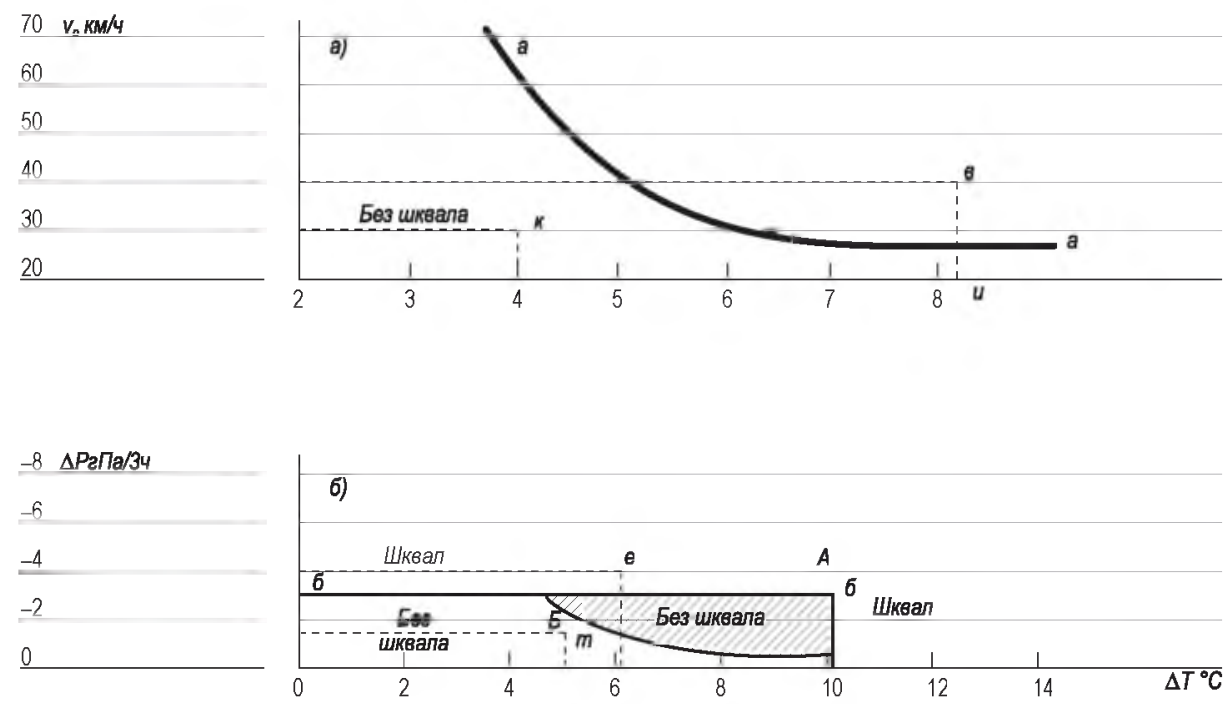

Рис. 9.

Графики определения ситуации шквалов различной силы.

Fig. 9. The graphs of defining the situation of different strength squalls [4] 


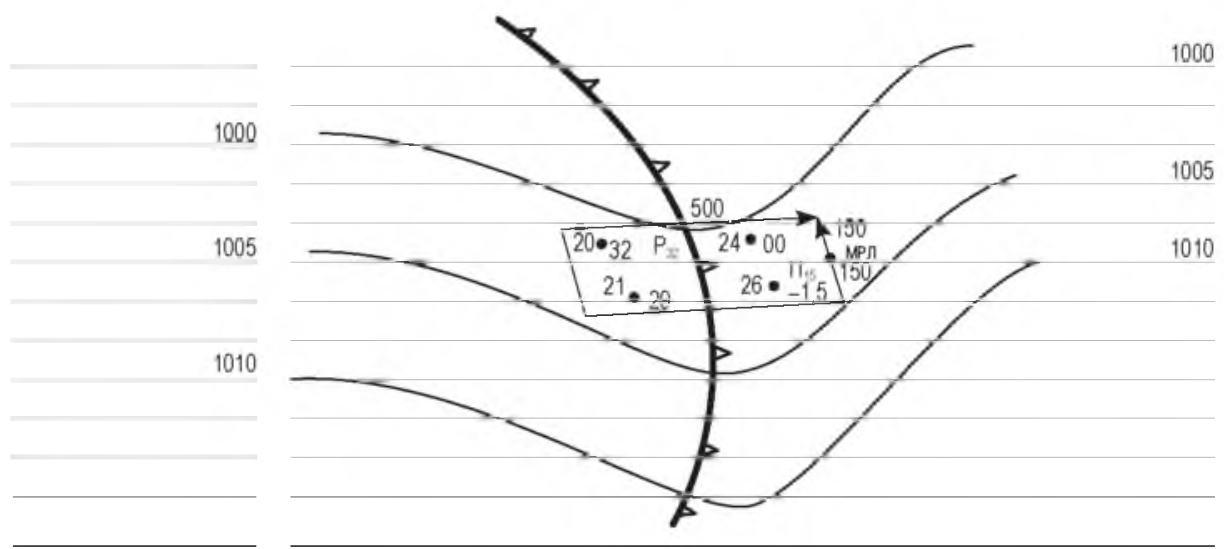

$\Delta \mathrm{P}=-1,5-3,2=-4,7 \Gamma \Pi \mathrm{\Gamma} / 34$

$\Delta \mathrm{T}=26-20=6^{\circ} \mathrm{C}$

Рис. 10. Расчет значений $\Delta P$ и $\Delta T$ в зоне фронта [4].

Fig. 10. The calculation of $\Delta P$ and $\Delta T$ values in the front zone [4].

В условиях, когда по данным МРЛ диагностируется шквал с $V>25$ м/с, возможно появление смерча, если $H_{\mathrm{B}} \geq 11 \mathrm{\kappa м}, \lg Z_{3} \geq 3, Z_{d m}^{\prime}=25 \mathrm{dBZ}$ и $\left(H-H_{\mathrm{T}}\right) \geq 1$; очаги радиоэха расположены грядами, которые быстро сближаются друг с другом.

\section{Выводы}

В результате анализа многолетних аэросиноптических материалов и материалов радиолокационных наблюдений, полученных в регионе Центрального Кавказа с помощью визуальных наблюдений и дистанционных методов зондирования атмосферы, выявлено 5 типов ПООС. К ним относятся: $\mathrm{Cu}-\mathrm{Cong}, \mathrm{Cb}, \mathrm{Ns}-\mathrm{As}, \mathrm{Ns}-\mathrm{As}-\mathrm{Cb}, \mathrm{Ns}-\mathrm{As}-\mathrm{Ac}$.

Значения параметров ПООС и характер их распределения в атмосфере и на поверхности Земли представлены в таблицах 1-3, на рисунках 1-5 и успешно используются в методах диагноза и сверхкраткосрочного прогноза опасных явлений погоды, работах по ПГЗ и ИУО.

Они позволяют с высокой вероятностью:

- у у у у уочнить классы ПООС для диагноза и сверкраткосрочного прогноза опасных явлений погоды (ливни, грозы, град, шквалы более $25 \mathrm{M} / \mathrm{c}$ );

оценить наблюдаемые в реальном масштабе времени типы градовых процессов, с целью выбора оптимальных площадок засева ПГР ОВ 1-4-й категорий $[1,5,6,20]$ : 

- $\quad$ разработать критерий объектов воздействия (OB) 1-4-й и уточнить нормы расхода льдообразующих реагентов в них в зависимости от геометрических и физических парамет- ров ОВ 1-4-й категорий [6];
разработать критерии пригодности ПООС для активных воздействий в работах по искусственному увеличению осадков и уточнить нормы расхода льдообразующих реа- гентов в них в зависимости от значений геометрических и физических параметров $[5,6]$.

Многие из вышеперечисленных проблем практически решены в работах автора [3-8, 14]. Они защищены патентом [4], одобрены Центральной методической комиссией по гидрометеорологическим прогнозам Госкомгидромета [3], внедрены на сети Госкомгидромета [14] и успешно применяются в работах по ПГЗ и ИУО [3-8, 16].

\section{Библиографический список}

1. Абшаев М.Т., Абшаев А.М., Малкарова А.М., Барекова М.В. Руководство по организации и проведению противоградовых работ. Нальчик: Печатный двор, 2014. 500 с.

2. Бартишвили Я.Т., Надибаидзе Г.А. Бегалишвили Н.А., Гудушаури Ш.Л. К физическим основам метода ЗакНИГМИ борьбы с градом // Труды ЗакНИГМИ. 1978. Вып. 67(73). С. 73-82.

3. Бочарников Н.В., Брылев Г.Б., Песков Б.Е., Ватиашвили М.Р., Хохлов ГВ. Методические указания по определению шквалов с использованием данных МРЛ. Л.: Гидрометеоиздат, 1988. 23 с.

4. Ватиашвили М.Р., Джангуразов Х.Х., Кассиров В.П. Способ активных воздействий на градовые процессы. Патент РФ на изобретение №2321871, заявка № 2006 121792, а 01 G 15.10.2007.

5. Ватиашвили М.P. Метод прерывания града на подступах защищаемой территории со стороны вторжения градовых облаков // Наука. Инновации. Технологии. 2016. №4. С. 7-24.

6. Ватиашвили М.Р. Метод прерывания града на защищаемых территориях региона Центрального Кавказа // Наука. Инновации. Технологии. 2018. №1. С. 7-22.

7. Ватиашвили М.Р. Обзор методов противоградовой защиты в регионе Центрального Кавказа // Наука. Инновации. Технологии. 2018. №3. C. 48-65.

8. Ватиашвили М.Р. Радиолокационная отражаемость облаков и осадков на различных длинах волн // Наука. Инновации. Технологии. 2017. №4. С. 105-118. 
9. Зверев А.С. Синоптическая метеорология и основы предвычисления погоды. Л.: Гидрометеоиздат, 1968. 711 с.

10. Карцивадзе А.И., Салуквадзе Т.Г., Лапинскас В.А. Некоторые вопросы методики воздействия на градовые процессы с использованием противоградовой системы «Алазани» // Труды института геофизики АН Грузии. 1975. Т. 26. С. 13-27.

11. Мазин И.П. О классификации облаков по их фазовому строению. Индекс фазового строения облаков // Метеорология и гидрология. 2001. №11. С. 5-11.

12. Матвеев Л.Т. Общая метеорология. Физика атмосферы. Л.: Гидрометеоиздат, $1976.639 \mathrm{c}$

13. Облака и облачная атмосфера. Справочник / под ред. И.П. Мазина и А.Х. Хргиана. Л.: Гидрометеоиздат, 1989. 647 с.

14. Руководство по производству наблюдений и применению информации с неавтоматизированных радиолокаторов МРЛ-1, МРЛ-2, и МРЛ-5. РД 52.04.320-91. СПб.: Гидрометеоиздат, 1993 $368 \mathrm{c}$.

15. Рунион Р. Справочник по непараметрической статистике: Современный подход / перевод с английского языка Е.З. Демиденко. М.: Финансы и кредит, 1982. 198 с.

16. Сванидзе Г.Г, Бегалишвили Н.А., Ватьян М.Р., Карцивадзе А.И. Гудушаури Ш.Л. Методические указания по организации и проведению работ по искусственному увеличению осадков из конвективных облаков с помощью противоградовой техники. М.: Гидрометеоиздат, 1986. 25 с.

17. Сулаквелидзе Г.К. Ливневые осадки и град. Л.: Гидрометеоиздат, $1967.421 \mathrm{c}$

18. Физика облаков / Под ред. А.Х. Хргиана и др. Л.: Гидрометеоиздат, 1969. 647 с.

19. Хргиан А.Х., Новожилова Н.И. Атлас облаков. Л.: Гидрометеоиздат, 1978. $268 \mathrm{c.}$

20. Chisholm A.J., Renik J.H. Supercell and murticell Alberta hailstorms // Proc. Inter Cloud Physic Conf., 1972. London. P. 62-68.

\section{References}

1. Abshaev M.T., Abshaev A.M., Malkarova A.M., Barekova M.V. Rukovodstvo po organizatsii i provedeniyu protivogradovykh rabot (The Manual on organizing and executing of anti-hail works). NaIchik: 000 «Pechatnyi dvor», 2014. 500 p.

2. Bartishvili Ya.T., Nadibaidze G.A., Begalishvili N.A., Gudushauri Sh.L. K fizicheskim osnovam metoda ZakNIGMI bor'by s gradom. (To the physical foundations of the ZakNIGMI method of hail control) // Trudy ZakNIGMI, Is. 67 (73), 1978. P. 73-82.

3. Bocharnikov N.V., Brylev G.B., Peskov B.E., Vatiashvili M.R. Khokhlov G.V. Metodicheskie ukazaniya po opredeleniyu shkvalov $s$ ispolzovaniem dannykh MRL (Study guide on measuring squalls using MRL data). L.: Gidrometeoizdat, 1988. 23 p. 
4. Vatiashvili M.R., Dzhangurazov Kh.Kh., Kassirov V.P. Sposob aktivnykh vozdeystviy na gradovye protsessy (The way of active influences on hail processes) // Patent RF na izobreteniye №2321871, zayavka № 2006 121792, a 01 G 15/10/ 2007 (Patent of the Russian Federation for invention №2321871, application № 2006 121792, a 01 G 15/10/ 2007).

5. Vatiashvili M.R. Metod preryvaniya grada na podstupakh zashchishchaiemoy territorii so storony vtorzheniya gradovykh oblakov (Method of interrupting hail at the approach lanes of the protected area from the direction of hail clouds invasion) // Nauka. Innovatsii. Tekhnologii (Science. Innovation. Technologies). 2016. №4. P. 7-24.

6. Vatiashvili M.R. Metod preryvaniya grada na zashchishchaemykh territoriyakh regiona Tsentralnogo Kavkaza (The method of hail breaking on the protected areas of the Central Caucasus region) // Nauka. Innovatsii. Tekhnologii (Science. Innovation. Technologies). 2018. №1. P. 7-22.

7. Vatiashvili M.R. Obzor metodov protivogradovoy zashchity $\vee$ regione Tsentralnogo Kavkaza (The review of methods of anti-hail protection in the Central Caucasus region) // Nauka. Innovatsii. Tekhnologii (Science. Innovation. Technologies). 2018. №3. P. 4865.

8. Vatiashvili M.R. Radiolokatsyonnaya otrazhaemost' oblakov i osadkov na razlichnych dlinakh voln (Radar reflection of clouds and precipitations at different wave lengths) // Nauka. Innovatsii. Tekhnologii (Science. Innovation. Technologies). 2017. №4. P. 105-118.

9. ZverevA.S. Sinopticheskaya meteorologiya i osnovy predvychisleniya pogody (Synoptic meteorology and foundaions of weather predictions). L.: Gidrometeoizdat, 1968. 711 p.

10. Kartsivadze A.I., Salukvadze T.G., Lapinskas V.A. Nekotorye voprosy metodiki vozdeistviya na gradovye protsessy s ispolzovaniem protivogradovoi sistemy «Alazani» (Some issues of method of affecting hail processes with anti-hail system «Alazani») // Trudy instituta geofiziki AN Gruzii. 1975. Is. 26. P. 13-27.

11. Mazin I.P. O klassifikatsii oblakov po ikh fazovomy stroeniyu. Indeks fazovogo stroeniya oblakov (About clouds classification on their phase composition. The index of clouds phase composition) // Meteorology and Hydrology. 2001. №11. P. 5-11.

12. Matveev L.T. Obshchaya meteorologiya. Fizika atmosfery. (General Meteorology. Aerophysics). L.: Gidrometeoizdat, 1976. 639 p.

13. Oblaka i oblachnaya atmosfera. Spravochnik (Clouds and cloud atmosphere. Reference book) / Pod red. I.P. Mazina and A.Kh. Khgiana. L.: Gidrometeoizdat, 1989. $647 \mathrm{p}$

14. Rukovodstvo po proizvodstvu nablyudenii i primeneniyu informatsii s neav-tomatizirovannykh radiolokatorov MRL-1, MRL-2 and MRL5 (Manual on making observations and using information from noncomputerized radars MRL-1, MRL-2 and MRL-5). RD 52. 04. 32091. SPb.: Gidrometeoizdat, 1993. 368 p. 
15. Runion R. Spravochnik po neparametricheskoy statistike: Sovremennyi podkhod (Handbook on Nonparametric Statistics: A Modern Approach) / perevod s angliyskogo yazyka Demidenko Ye.Z. (Translation from English Demidenko Ye.Z.). M.: Finansy i kredit 1982. 198 p.

16. Svanidze G.G., Begalishvili N.A., Vatian M.R., Kartsivadze A.I. Gudushauri Sh.L. / Metodicheskie ukazaniya po organizatsii i provedeniyu rabot po iskusstvennomu uvelicheniyu osadkov iz konvektivnykh oblakov s pomosh'yu protigradovoy tekhniki. (Study guide on arranging and carrying out activities on artificial increasing of weather precipitations from convective clouds by means of anti-hail equipment) // M.: Gidrometeoizdat, 1986. 25 p.

17. Sulakvelidze G.K. / Livnevye osadki i grad (Cloud bursts and hailing). L.: Gidrometeoizdat, 1967. 421 p.

18. Fizika oblakov (The Physics of clouds) / Pod. Red. A.Kh. Khrgiana i dr. L.: Gidrometeoizdat, 1969. 647 p.

19. Khrgian A.Kh., Novozhilova N.I. Atlas oblakov (The Clouds Atlas) L.: Gidrometeoizdat, 1978. 268 p.

20. Chisholm A.J., Renik J.H. Supercell and murticell Alberta hailstorms // Proc. Inter Cloud Physic Conf., 1972. London. P. 62-68.

Рукопись поступила в редакцию 13.12.2018 г. Принята к публикации 25.02.2019 г.

\section{Сведения 06 авторе}

Ватиашвили Михаил Рубенович. Кандидат географических наук, Доцент, Грузинский государственный научно-технический центр «Дельта» министерства обороны Грузии.

Грузия, г. Тбилиси, ул. Габриеля Салоса, 191.

Научный консультант по проектам.

\section{About the author}

Vatiashvili Mikhail Rubenovich Candidate of geographical sciences The senior lecturer Georgian state scientific and technological center "Delta" Ministries of Defence of Georgia Scientific consultant for projects +995 598-341-451.

Mivv123@mail.ru 191 Monk Gabriel Salos Ave. 0144 